\title{
Illuminating the volcanic signal in tree rings
}

Alexander R. Stine', M.P. Tingley ${ }^{2}$ and P. Huybers ${ }^{3}$

\section{Comparison of the signature of volcanism in tree rings with thermometers indicates that tree rings overestimate volcanic cooling. The timing and spatial expression of the tree-ring response indicate that decreased light availability contributes to the tree-ring response to volcanism.}

Volcanic eruptions that loft aerosols into the stratosphere offer natural experiments by which to explore the response of the climate system to short-term changes in radiative forcing. In the one to two years following the largest volcanic eruptions of the past century, we observe a decrease in the solar radiation received at the Earth's surface, as well as cooler than usual surface temperatures (Robock et al. 2007). Volcanic eruptions also offer an opportunity to explore the response of tree-ring proxies to changes in solar radiation and temperature. Most tree-ring chronologies from temperature-limited high-northern latitude regions show a decrease in tree-ring width or density following a major explosive volcanic eruption. This response has historically been interpreted as an exclusive result of the cooler summertime temperatures that are observed following such eruptions - a cooling that is understood to be induced by scattering from volcanic aerosols in the stratosphere that reduce the amount of shortwave radiation reaching the Earth's surface.

An emerging line of evidence supports the hypothesis that high-latitude treering growth also responds to variability in light, independent of the influence of light on temperature (Stine and Huybers 2014; Tingley et al. 2014). The notion that large-scale tree-ring growth may respond to changes in photosynthetic light availability is not new (Briffa et al. 1998). Indeed, the well-established Vaganov-Shashkin (VS) model of tree-ring growth includes a term whereby the growth rate is proportional to variations in daily average light intensity (Vaganov et al. 2006).

Here we discuss two lines of evidence for a direct tree-ring response to volcanic dimming. Each relies on aggregating the treering response to large volcanic eruptions over distinct regions of the Arctic, so as to isolate the effects of reduced light from the effects of cooler temperatures (Stine and Huybers 2014; Tingley et al. 2014).

\section{Evidence that light affects trees}

One line of evidence that tree rings respond to changes in the light environment is provided by comparing the volcanic temperature response inferred from tree rings to that measured by thermometers. Consider the response to the 1883 Krakatoa and 1912 Novarupta eruptions - the two largest eruptions that occurred late enough to be reasonably well-monitored by instrumental thermometers, but early enough to be unaffected by the late- $20^{\text {th }}$ century decline in Arctic tree-ring width and density relative to temperature referred to as the divergence phenomenon (Briffa et al. 1998). Both Krakatoa and Novarupta resulted in strong reductions in atmospheric transmissivity, leading to a reduction in surface solar radiation intensity which was recorded by contemporary pyrheliometer measurements (Kimball 1918). In both cases post-eruption temperature anomalies inferred from tree-ring densities show a larger amplitude response than is consistent with the degree of cooling found in thermometer measurements (Fig. 1; Tingley et al. 2014). Furthermore, the cold bias is larger in magnitude in high-latitude regions where photosynthesis is inferred to be more limited by light (Nemani et al. 2003), supporting the hypothesis that trees respond directly to decreases in light availability. Pyrheliometer measurements indicate that the atmospheric transmissivity was reduced for substantially longer following Krakatoa ( 3 years) than following Novarupta ( 1 years; Kimball 1918). In both cases the tree-ring cold bias persists for a period similar to the period of reduced atmospheric transmissivity (Fig. 1e,f).

Whereas the instrumental period contains only a small number of eruptions with a clear response in both the instrumental and tree ring records, 32 major eruptions were recorded in the northern hemisphere ice-core record in just the last 700 years (Gao et al. 2007). Across the high-northern latitudes a close correspondence exists between the magnitude of the tree-ring response to volcanism and estimates of the relative importance of light availability in limiting plant growth (Fig. 2c; Nemani et al. 2003). The reduction in tree-ring density following the major volcanic eruptions of the last 700 years was, on average, twice
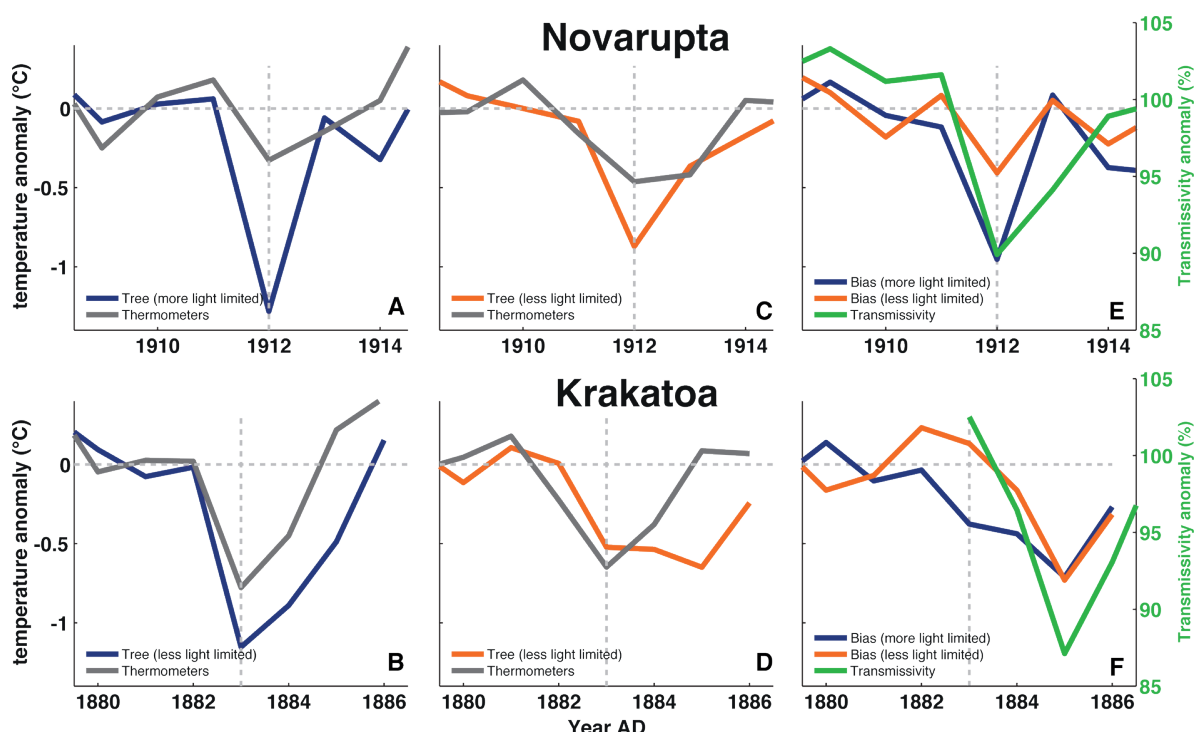

Figure 1: Comparison of the volcanic cooling recorded by boreal tree rings with volcanic cooling recorded by thermometers. Tree rings are calibrated into temperature units using a Bayesian approach (Tingley et al. 2014). Top row shows response for 1912 Novarupta eruption and bottom row for 1883 Krakatoa eruption. (A and B) Comparison for relatively strongly, and (C and $\mathbf{D}$ ) for relatively weakly light-limited boreal regions. (E and F) The bias in the tree-ring response from regions of relatively strong (blue) and weak (orange) light-limitation compared with the anomaly in atmospheric transmissivity inferred from contemporary pyrheliometers (green; Kimball 1918). 
as large in high-northern latitude regions where light-limitation on photosynthesis is strong, compared with regions where light limitation on photosynthesis is weaker (Fig. 2a). Similar results are found for tree-ring widths (Stine and Huybers 2014). The concordance between the volcanic response and patterns of light limitation to growth suggests that, in the boreal regions that are more strongly light limited, tree growth responds directly to both the reduction in temperature and the reduction in photosynthetically available radiation.

\section{Light and growth}

There are a number of different frameworks for thinking about the role of light variability in modulating productivity, not all of which can be considered entirely consistent with each other. Manipulation studies have directly shown that tree-ring growth in the tropics increases in response to increased light availability (Graham et al. 2003). The Carnegie Ames Stanford Approach (CASA) carbon cycle model treats productivity as directly proportional to light availability, multiplied by a growth limitation term which may be controlled by temperature or moisture availability depending on local environmental conditions (Potter et al. 1993). The VS model of tree-ring growth incorporates this formulation as well (Vaganov et al. 2006). Satellitebased estimates of productivity assume proportionality to surface insolation and infer the efficiency at which this light is used from the spectra of surface reflectance (Running et al. 2004). Global climate models include light limitation as one of several competing forms of environmental limitation that can modulate carbon uptake. Laboratory-based studies of photosynthesis, in contrast, tend to emphasize the ability of photosynthesis to proceed at a constant rate across a broad range of light intensities (Long et al. 1994).

\section{Global dimming}

Two lines of evidence - the spatial pattern of the volcanic tree-ring response, and the difference between this response in tree rings and in thermometer measurements support the notion that a reduction in solar radiation will lead to a decrease in growth in some tree-ring records.

From 1955-1975, a reduction in shortwave radiation was observed in many regions of the world, including at high-northern latitudes (Wild 2009). Over this same period, tree-ring density in many boreal regions exhibited a negative trend relative to temperature. Interestingly, the pattern of these trends in tree-ring growth relative to temperature is correlated with the pattern of tree-ring density anomalies following volcanic eruptions (Fig. 2b,d).

A competing interpretation exists, which indicates that divergence results from methodological and data treatment decisions (Esper et al. 2010). However, a simulation using synthetic data showed that the imprint of a global dimming on tree-ring growth is more clearly detectable when,
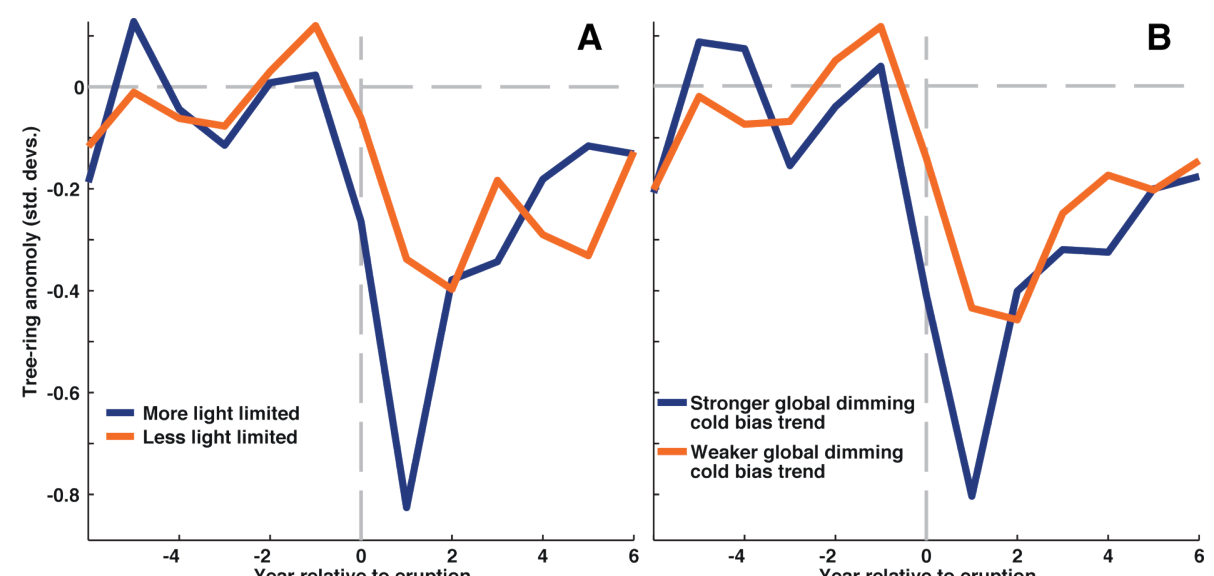

B
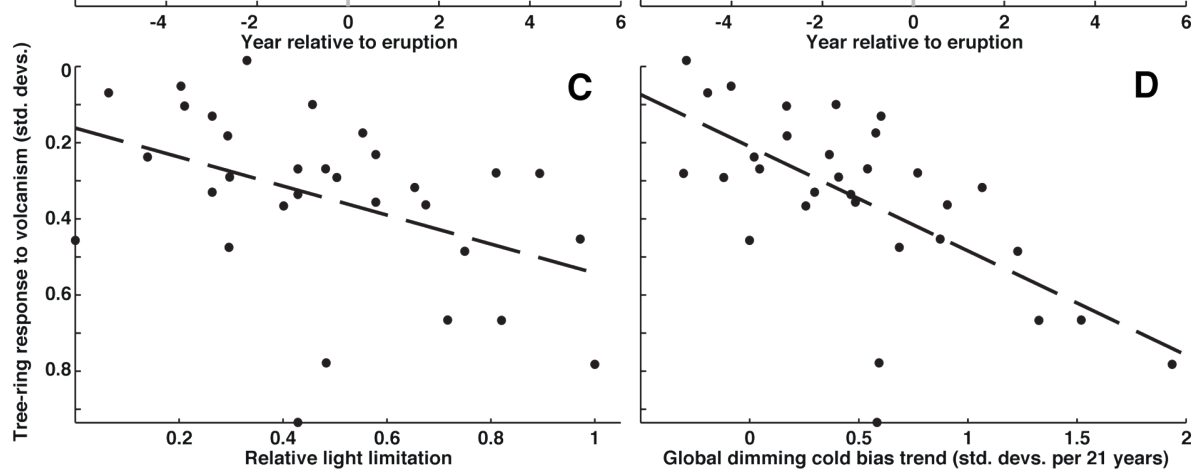

Figure 2: Comparison of the tree-ring density response to volcanic eruptions of the last 700 years with local estimates of light limitation and spatial variability in the response to global dimming (Stine and Huybers 2014). (A) Volcanic response in strongly (blue) and weakly (orange) light-limited regions. (B) Volcanic response in regions with strong (blue) and weak (orange) decline in density relative to temperature during period of global dimming. Comparison of volcanic tree-ring response to (C) light limitation and to (D) global dimming across the boreal region.

instead of using a difference methodology (Esper et al. 2010), a regression approach is employed to isolate non-temperature components in the tree-ring record (Stine and Huybers 2014). This regression approach indicates a significant imprint of global dimming on Arctic tree-ring growth over the period of divergence. Further work testing for the presence of divergence and its characteristics is warranted.

\section{Outlook}

The signature of a changing light environment in the tree-ring record implies that tree rings reflect both the climatic cooling in response to volcanism, and, via dimming, the forcing itself. Tree-ring scientists have traditionally worked hard to isolate trees that respond primarily to a single environmental control, maximizing the ability to reconstruct that variable. Increasingly, however, advances in tree-ring science allow interpretation of multiple proxies from the same cores. For example, stable carbon isotope ratios record variability in stomatal conductance, which may be controlled by light availability and moisture stress (Gagen et al. 2011). Wood anatomy measurements of features such as cell lumen area and cell wall thickness, can reveal environmental information distinct from that inferred from tree-ring width. These indications of the contribution of light variability to high-latitude tree-ring records makes it only more important that tree-ring scientists continue to develop these new proxies, so that we can more fully separate the signature of light variability from temperature variability in the tree-ring record.

\section{AFFILIATIONS}

'Department of Earth \& Climate Sciences, San Francisco State University, USA

${ }^{2}$ Department of Statistics and Department of Meteorology, Penn State University, State College, USA

${ }^{3}$ Department of Earth and Planetary Sciences, Harvard University, Cambridge, USA

\section{CONTACT}

Alexander Stine: stine@sfsu.edu

\section{REFERENCES}

Briffa K et al. (1998) Nature 391: 678-682

Esper J et al. (2010) Global Change Biol 16: 386-398

Gagen M et al. (2011) Geophys Res Lett 38: L05701

Gao C et al. (2007) J of Geophys Res 112, doi:10.1029/2010GL046216

Graham E et al. (2003) PNAS 100: 572-576

Kimball H (1918) Mont Weather Rev 46: 355-356

Long S et al. (1994) Annu Rev Plant Biol 45: 633-662

Nemani R et al. (2003) Science 300: 1560-1563

Potter C et al. (1993) Global Biogeochem Cycles 7:

$$
811-841
$$

Robock A (2007) Rev Geophys 45: 191-220

\section{Running S et al. (2004) Bioscience 54: 547-560}

Stine A, Huybers P (2014) Nat Commun 5, doi:10.1038/ ncomms4836

Tingley M et al. (2014) Geophys Res Lett 41: 7838-7845

Vaganov E et al. (2006) Growth dynamics of conifer tree rings, Springer, 354pp

Wild M (2009) J Geophys Res 114, doi:10.1029/2008JD011470 